\title{
Removal of molybdenum from wastewater using modified amino-functional framework: a study of the adsorption properties
}

Mahdie Saghian

Alzahra University

Saeed Dehghanpour ( $\nabla$ dehghanpours@alzahra.ac.ir)

Alzahra University https://orcid.org/0000-0002-3042-5240

Massoomeh Sharbatdaran

Nuclear Sciences and Technology Research Institute

\section{Research Article}

Keywords: Metal organic framework, Molybdenum adsorption, Post-synthetic modification, High adsorption capacity, Superior adsorbent

Posted Date: October 26th, 2021

DOI: https://doi.org/10.21203/rs.3.rs-1005268/v1

License: (c) (i) This work is licensed under a Creative Commons Attribution 4.0 International License. Read Full License 


\title{
Removal of molybdenum from wastewater using modified amino-functional
} framework: a study of the adsorption properties

\author{
Mahdie Saghian, ${ }^{a}$ Saeed Dehghanpour*a and Massoomeh Sharbatdaran ${ }^{\mathrm{b}}$ \\ ${ }^{\text {a }}$ Department of chemistry, Alzahra University, P.O. Box 1993891176, Tehran, Iran. \\ ${ }^{\mathrm{b}}$ Nuclear Sciences and Technology Research Institute, Karaj, Iran. \\ * E-mail: Dehghanpours@alzahra.ac.ir; Fax: +982188041344
}




\begin{abstract}
Herein, we have employed a convenient method to study kinetic and thermodynamic parameters of the adsorption of molybdenum from wastewater by using modified Zr-based metal-organic frameworks, UIO-66- $\mathrm{NH}_{2}-\mathrm{X}$, as adsorbents. The frameworks were fabricated with a simple and fast method from terephthalic acids and Zirconium metal ions and modified via introduction of aldehyde groups using imine condensation. This is the first report in which MOFs have been utilized as adsorbents in molybdenum adsorption. The prepared adsorbents show high adsorption efficiency which is representative of an improvement compared to other literature. The experimental adsorption data could be well interpreted with the pseudo-second-order kinetics and the Langmuir isotherm model. Thermodynamic studies illustrated an exothermic spontaneous mechanism for the adsorption process.
\end{abstract}

Keywords: Metal organic framework; Molybdenum adsorption; Post-synthetic modification; High adsorption capacity; Superior adsorbent.

\title{
Introduction
}

Molybdenum is one of the active transition elements with the biological application as well as used in industry [1]. It is a vital nutrient for both humans and plants. In plants, it is indispensable to fix atmospheric nitrogen and convert nitrate into nitrite, while in humans it is needed for removing toxins and activating enzymes[2, 3]. On the other hand, from industrial viewpoint, molybdenum has miscellaneous functions such as vacuum tubes, alloying agents, rubber, catalysts, and solid lubricants. However, the excess effluent concentration of molybdenum in water caused crucial environmental problems. Therefore the removal of molybdenum from wastewater is essential in order to eliminate its hazardous impact on the environment[4]. 
Different oxidation states of Molybdenum vary from Mo(II) to Mo(VI) exist in wastewater which among them molybdate ion $\left(\mathrm{MoO}_{4}{ }^{2-}\right)$ is the most soluble species. One of the most significant radionuclides is Molybdenum-99 $\left({ }^{99} \mathrm{Mo}\right)$ which is used in nuclear medicine. ${ }^{99} \mathrm{Mo}$ is one of the toxic compounds in radioactive waste that need to be removed in order to the protection of people and the environment $[5,6]$.

Various methods have been investigated for molybdenum removal from wastewater such as adsorption process, ion exchange, electrochemical techniques, and biological treatment. So far, among diverse available wastewater treatments, adsorption process is significant due to its effectiveness and suitable economical condition[7-9].

Many different adsorbents have been developed and applied in order to eliminate Mo(VI) from wastewater such as carbon nanotubes, pyrite, ferric oxide gel, chitosan, ion exchange resin, and etc[10-12].

Metal-organic frameworks (MOFs) are a new class of porous materials that have attracted significant attention of many researchers in recent years due to their unique and special characteristics including high surface area and porosity, tunable pore structure, high thermal stability, and different accessible sites. These compounds are formed via the auto-assemblage of metal ion clusters and polyfunctional organic linkers. Up to now, they have widely employed in numerous applications such as catalysis, sensing, adsorption, sequestration, drug delivery, and etc[13-17]. In particular, they have great potential to be as an adsorbent for heavy metal wastewater treatment. Although MOFs are applied to adsorb various metals from wastewater, no research has been reported on molybdenum adsorption by MOFs so far. 
Based on the above consideration, in this work, the adsorption studies on molybdenum pollutant from wastewater was investigated over modified MOFs. Therefore, UIO-66- $\mathrm{NH}_{2}$ has been successfully synthesized and modified with aldehyde functional groups using imine condensation (Scheme 1). The adsorption capacity, kinetics, and thermodynamic have been evaluated in detail. Additionally, the equilibrium data were analyzed by using Langmuir isotherms. The details of the adsorption process and its effective factors will be discussed.

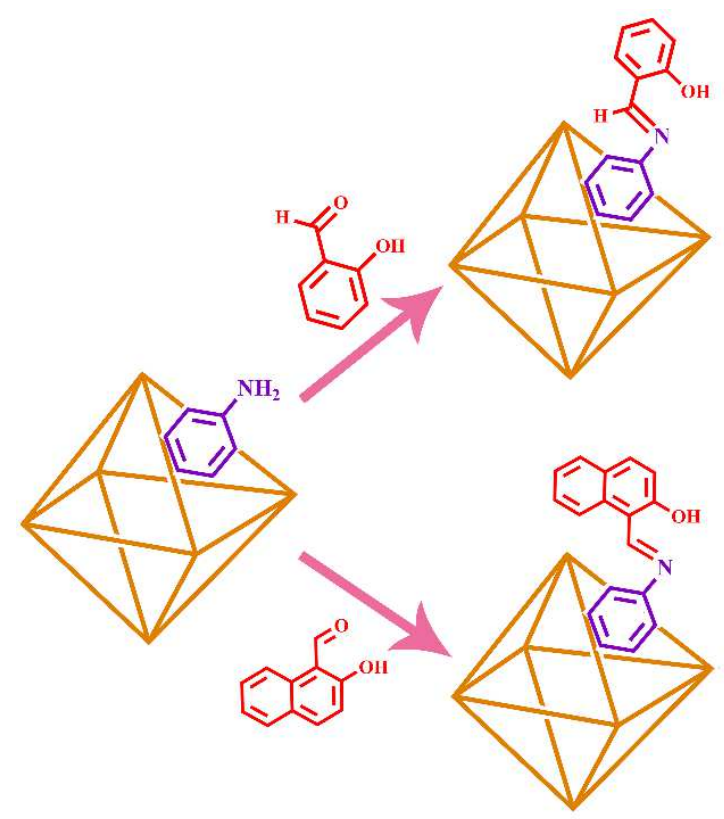

Scheme 1 Synthesis of modified UIO-66- $\mathrm{NH}_{2}$.

\section{Experimental}

Materials and instrumentation

Materials and instrumentation are explained in supporting information.

\section{Synthesis of adsorbents}

Synthesis of UIO-66- $\mathrm{NH}_{2}$ 
UIO-66- $\mathrm{NH}_{2}$ was synthesized according to the previously reported procedure[18]. In a typical procedure, zirconium (IV) chloride (0.6 g, $2.75 \mathrm{mmol})$ were suspended in $25 \mathrm{ml}$ of dimethylformamide, followed by the addition of $5 \mathrm{ml}$ of $\mathrm{HCl}$. The following mixture ultrasounded for $5 \mathrm{~min}$ to obtain clear solution. 2-aminoterephthalic acid $(0.6 \mathrm{~g}, 3.75 \mathrm{mmol})$ was dissolved in $50 \mathrm{ml}$ dimethylformamide and added to the metal salt solution. The reaction mixture was refluxed at $80{ }^{\circ} \mathrm{C}$ for $24 \mathrm{~h}$. The resulting yellow powder was separated, washed with dimethylformamide and activated at $150{ }^{\circ} \mathrm{C}$ for $24 \mathrm{~h}$.

Synthesis of UIO-66- $\mathrm{NH}_{2}-\mathrm{SA}$

Activated UIO-66- $\mathrm{NH}_{2}(0.8 \mathrm{~g})$ was suspended in $20 \mathrm{ml}$ of absolute ethanol, followed by the addition of $0.5 \mathrm{ml}(4.8 \mathrm{mmol})$ salicylaldehyde. The following mixture was refluxed at $80{ }^{\circ} \mathrm{C}$ for $20 \mathrm{~h}$. The sharp yellow solid obtained was filtered, washed with ethanol and dried at $60{ }^{\circ} \mathrm{C}$ for 4 h.

Synthesis of UIO-66- $\mathrm{NH}_{2}-\mathrm{OH}$

Activated UIO-66- $\mathrm{NH}_{2}(0.8 \mathrm{~g})$ was added to a solution containing $1.30 \mathrm{~g}(7.5 \mathrm{mmol})$ of 2 hydroxynaphthaldehyde in $30 \mathrm{ml}$ ethanol, the suspension was the refluxed for $20 \mathrm{~h}$. The resulting precipitate was separated, washed with ethanol and dried at $60{ }^{\circ} \mathrm{C}$ for $4 \mathrm{~h}$.

\section{Molybdenum adsorption experiments}

The adsorption studies of molybdenum (Mo) from aqueous solution were conducted by using the batch technique over prepared UIO-66- $\mathrm{NH}_{2}$, UIO-66- $\mathrm{NH}_{2}-\mathrm{SA}$ and UIO-66- $\mathrm{NH}_{2}-\mathrm{OH}$ frameworks as adsorbent. In this procedure, $100 \mathrm{mg}$ of the freshly prepared adsorbent was added to a $25 \mathrm{ml}$ of the solution containing ammonium heptamolybdate with different initial concentrations (20-200 $\mathrm{mg} \cdot \mathrm{L}^{-1}$ ), the suspension was stirred at room temperature for a preselected period of time. After the 
completion of the adsorption process, the adsorbent was filtered and the amount of residual Mo ion in the solution was monitored by ICP analysis. Furthermore, the temperature, adsorption time and $\mathrm{pH}$ were also optimized. The amount of adsorbed Mo at equilibrium $\left(q_{e}\right)$ was calculated by the following equation:

$q_{e}=\frac{v\left(c_{0}-c_{e}\right)}{m}$

Where $\mathrm{C}_{0}$ and $\mathrm{C}_{\mathrm{e}}$ are the initial and the equilibrium concentration $(\mathrm{mg} / \mathrm{L})$, respectively. $\mathrm{V}$ is the volume of the solution $(\mathrm{L})$ and $\mathrm{m}$ is the weight of adsorbent $(\mathrm{g})$.

\section{Results and discussion}

In the present work, UIO-66- $\mathrm{NH}_{2}$ was synthesized and successfully modified with aldehyde groups using imine condensation reaction (Scheme 1) in order to make a superior adsorbent for removal of molybdenum from wastewater.

\section{Characterization of adsorbents}

The FT-IR spectra of the prepared compounds are depicted in Fig. S1. The FT-IR spectrum of UIO-66- $\mathrm{NH}_{2}$ (Fig. S1a) exhibits characteristic bands at 1388 and $1641 \mathrm{~cm}^{-1}$ which is attributed to the symmetric and asymmetric stretching vibrations of the carboxylic acid functional group, respectively. Additionally, the bands appeared around 719 and $761 \mathrm{~cm}^{-1}$ can be associated with the out-of-plane deformation vibration of $\mathrm{C}-\mathrm{H}$ groups in the phenyl rings of 2-aminoterephthalic acid linkers[19]. In the FT-IR spectra of UIO-66- $\mathrm{NH}_{2}-\mathrm{SA}$ and UIO-66- $\mathrm{NH}_{2}-\mathrm{OH}$ (Figs. S1b and S1C), the absence of the relevant band for the $\mathrm{C}=\mathrm{N}$ stretching vibration at $1640 \mathrm{~cm}^{-1}$ is owing to the overlapping with the asymmetric $\mathrm{COO}$ stretching vibrations. 
The crystalline nature of the prepared structures was investigated by powder X-ray diffraction (PXRD) analysis and the results are represented in Fig. 1. Based on the comparison of the main diffraction peaks of the as-synthesized and simulated structures, the structural accommodation of compounds can be concluded and no apparent loss of crystallinity was observed. Furthermore, it can be observed that topology and crystallinity of the structures have retained upon modification of the framework[18].

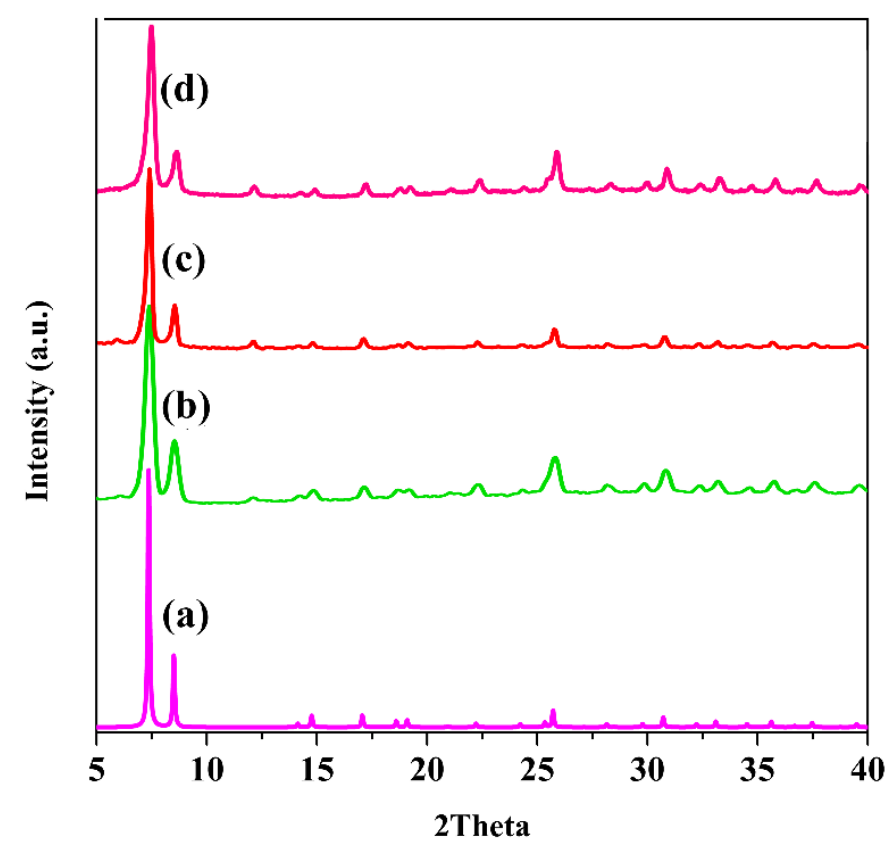

Fig. 1 XRD patterns of UIO-66- $\mathrm{NH}_{2}$ (a) simulated (b) as-synthesized, and (c) UIO-66- $\mathrm{NH}_{2}-\mathrm{SA}$ and (d) UIO-66- $\mathrm{NH}_{2}-$ $\mathrm{OH}$.

To specify the morphology and particle size of synthesized compounds, scanning electron microscopy (SEM) was conducted and the micrographs are presented in Fig. S2. The SEM images indicate uniform particle size of about $100 \mathrm{~nm}$ for UIO-66- $\mathrm{NH}_{2}$ (Fig. S2a and b). In addition, there is no substantial changes in the morphology of the structures after modification of the framework (Fig. S2c and d).

Thermal and structural stability of the synthesized frameworks were investigated by using of thermogravimetric analysis (TGA) and the results are illustrated in Fig. 2. The TGA curves show 
a two-step weight loss for the prepared compounds. As can be seen in Fig.2, the first weight loss for the as- synthesized UIO-66- $\mathrm{NH}_{2}$ occurred at about $60-120{ }^{\circ} \mathrm{C}$ which was related to the removal of guest molecules from the framework. The second weight loss is related to the thermal decomposition of the framework which occurred at about $400{ }^{\circ} \mathrm{C}$.

In the case of UIO-66- $\mathrm{NH}_{2}-\mathrm{SA}$ and UIO-66- $\mathrm{NH}_{2}-\mathrm{OH}$ after molybdenum adsorption, their residual mass is in accordance with the amount of Molybdenum adsorption by ICP (Fig. 2).

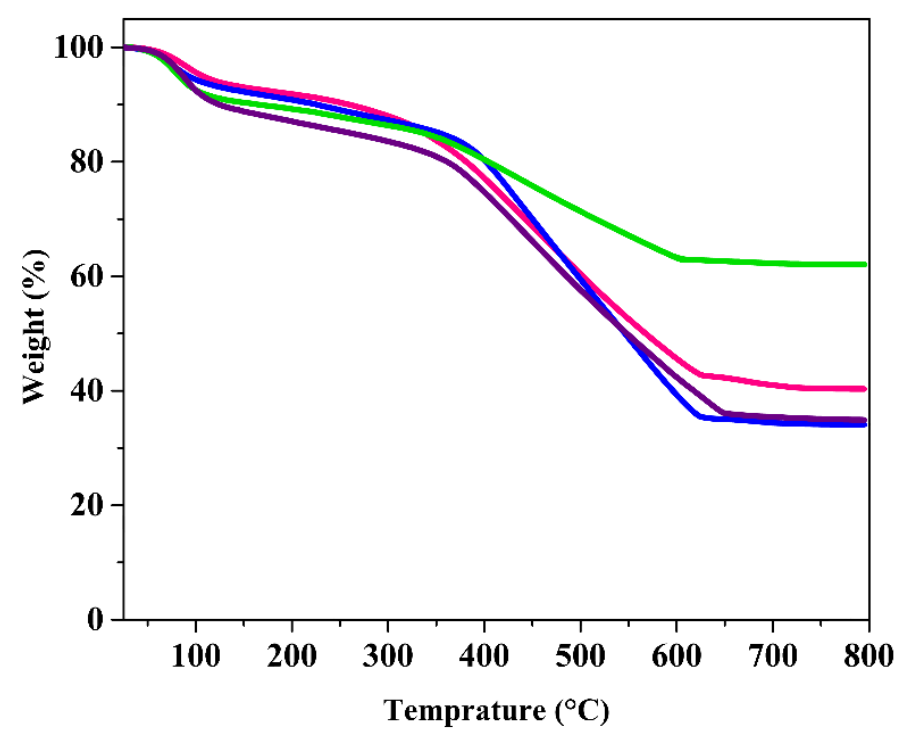

Fig. 2 TGA curves of UIO-66- $\mathrm{NH}_{2}$ (pink), UIO-66- $\mathrm{NH}_{2}-\mathrm{SA}$ (purple), UIO-66- $\mathrm{NH}_{2}-\mathrm{OH}$ (blue), UIO-66- $\mathrm{NH}_{2}-\mathrm{SA}$ after molybdenum adsorption (green).

To determine the specific surface area, porosity, and the pore volume of the prepared frameworks, $\mathrm{N}_{2}$ adsorption-desorption analysis at low temperatures was assessed and the results are summarized in Fig. 3 and Table 1. The $\mathrm{N}_{2}$ adsorption-desorption isotherms exhibited type I isotherms for both pristine MOF and modified frameworks. According to the values of textural parameters in Table 1, the surface area and pore volume for UIO-66- $\mathrm{NH}_{2}$ were $886 \mathrm{~m}^{2} / \mathrm{g}$ and $0.45 \mathrm{~cm}^{3} / \mathrm{g}$, respectively, whereas a substantial decrease for the corresponding values was observed owing to the modification of the framework. Therefore, the surface area and pore volume for UIO- 
66- $\mathrm{NH}_{2}-\mathrm{SA}$ and UIO-66- $\mathrm{NH}_{2}-\mathrm{OH}$ decreased to $574 \mathrm{~m}^{2} / \mathrm{g}$ and $0.31 \mathrm{~cm}^{3} / \mathrm{g}$, and $436 \mathrm{~m}^{2} / \mathrm{g}$ and 0.25 $\mathrm{cm}^{3} / \mathrm{g}$, respectively which affirmed the successful modification of the framework.

Table 1 Textural parameters of UIO-66- $\mathrm{NH}_{2}$ and modified structures.

\begin{tabular}{|c|c|c|c|}
\hline Entry & Sample & $\begin{array}{l}\mathrm{S}_{\mathrm{BET}} \\
\left(\mathrm{m}^{2} \cdot \mathrm{g}^{-1}\right)\end{array}$ & $\begin{array}{l}\text { Pore volume } \\
\left(\mathrm{cm}^{3} \cdot \mathrm{g}^{-1}\right)\end{array}$ \\
\hline 1 & UIO-66- $\mathrm{NH}_{2}$ & 886 & 0.45 \\
\hline 2 & UIO-66-NH2-SA & 574 & 0.31 \\
\hline 3 & UIO-66- $\mathrm{NH}_{2}-\mathrm{OH}$ & 436 & 0.25 \\
\hline 4 & $\begin{array}{ll}\text { UIO-66- } \mathrm{NH}_{2}-\mathrm{SA} & \text { after } \\
\text { molybdenum adsorption } & \\
\end{array}$ & 511 & 0.28 \\
\hline 5 & $\begin{array}{ll}\mathrm{UIO}-66-\mathrm{NH}_{2}-\mathrm{OH} & \text { after } \\
\text { molybdenum adsorption } & \\
\end{array}$ & 374 & 0.23 \\
\hline
\end{tabular}

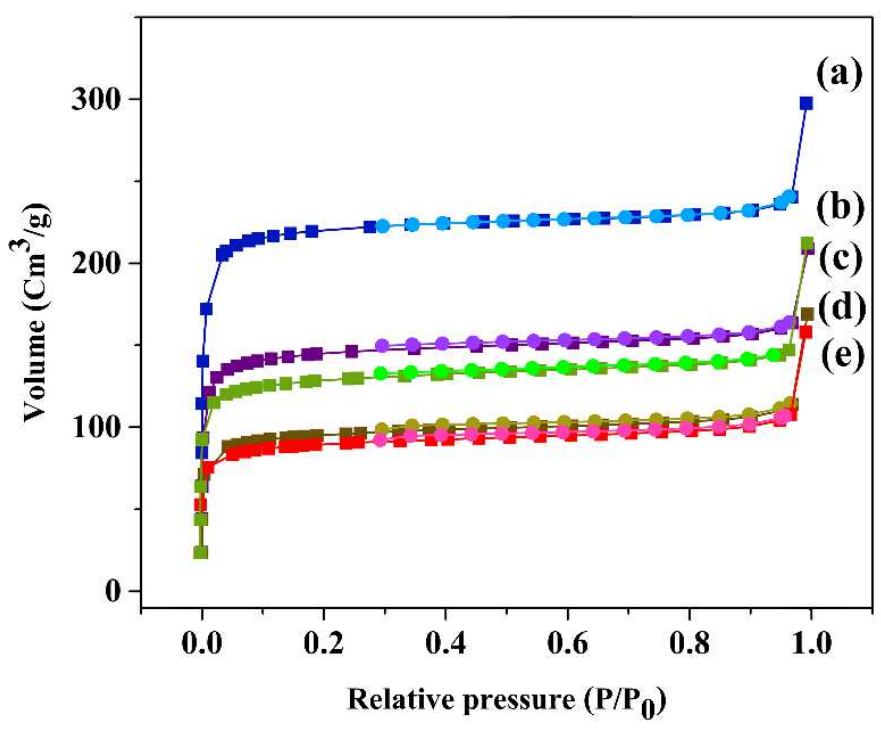

Fig. $3 \mathrm{~N}_{2}$ adsorption-desorption isotherms of (a) UIO-66- $\mathrm{NH}_{2}$, (b) UIO-66- $\mathrm{NH}_{2}-\mathrm{SA}$, (c) UIO-66-NH$-\mathrm{OH}$, (d) UIO66- $\mathrm{NH}_{2}-\mathrm{SA}$ after molybdenum adsorption, and (e) UIO-66- $\mathrm{NH}_{2}-\mathrm{OH}$ after molybdenum adsorption.

Adsorption study of the synthesized frameworks

To evaluate the adsorption proficiency of the prepared frameworks, the adsorption of Mo was studied using UIO-66- $\mathrm{NH}_{2}-\mathrm{SA}$ and UIO-66- $\mathrm{NH}_{2}-\mathrm{OH}$ as the adsorbents. The pristine MOF (UIO- 
66- $\mathrm{NH}_{2}$ ) have no capability for Mo adsorption. Therefore, the adsorption process was only performed with modified frameworks. Additionally, the effect of contact time, temperature, $\mathrm{pH}$, pollutant concentration, and the amount of adsorbents was also investigated in the adsorption process.

\subsection{Molybdenum removal ability of the synthesized compounds}

The removal of molybdenum from wastewater (Mo. R.) was calculated by the following equation:

Mo. R. $(\%)=\frac{\left(c_{0}-c_{t}\right)}{c_{0}} * 100$

Where $\mathrm{C}_{0}$ and $\mathrm{C}_{\mathrm{t}}$ are the initial and the final concentration at contact time $\mathrm{t}(\mathrm{mg} / \mathrm{L})$, respectively.

The results of the adsorption capacity and the amount of removed Mo are summarized in Table 2 . According to the results, high Mo removal and adsorption capacity were observed for both adsorbents due to the modification of the framework. However, the adsorption performance of UIO-66- $\mathrm{NH}_{2}-\mathrm{SA}$ is slightly better than UIO-66- $\mathrm{NH}_{2}-\mathrm{OH}$.

Table 2 The molybdenum removal ability of the synthesized frameworks.

\begin{tabular}{lll}
\hline Adsorbent & $\begin{array}{l}\text { Molybdenum } \\
\text { removal \% }\end{array}$ & $\begin{array}{l}\text { Adsorption } \\
\text { capacity }{ }^{\mathrm{a}}(\mathrm{mg} / \mathrm{g})\end{array}$ \\
\hline $\mathrm{UIO}-66-\mathrm{NH}_{2}-\mathrm{SA}$ & 93 & 667 \\
\hline $\mathrm{UIO}-66-\mathrm{NH}_{2}-\mathrm{OH}$ & 91 & 500 \\
\hline
\end{tabular}

a Reaction condition: catalyst (100 mg), Room temperature, Neutral pH

On the other hand, the results of $\mathrm{N}_{2}$ adsorption-desorption isotherms and textural parameters for modified frameworks after the adsorption of molybdenum indicate that molybdenum was adsorbed in both modified frameworks (Table 1, Entries 4 and 5). The surface area and pore volume for UIO-66- $\mathrm{NH}_{2}-\mathrm{SA}$ and UIO-66- $\mathrm{NH}_{2}-\mathrm{OH}$ after molybdenum adsorption decreased to $511 \mathrm{~m}^{2} / \mathrm{g}$ and 
$0.28 \mathrm{~cm}^{3} / \mathrm{g}$, and $374 \mathrm{~m}^{2} / \mathrm{g}$ and $0.23 \mathrm{~cm}^{3} / \mathrm{g}$, respectively which confirmed the adsorption of molybdenum.

\section{Effect of different parameters on adsorption of molybdenum}

\section{The influence of contact time on the molybdenum adsorption}

The effect of contact time on Mo adsorption was investigated using UIO-66- $\mathrm{NH}_{2}-\mathrm{SA}$ and UIO$66-\mathrm{NH}_{2}-\mathrm{OH}$ at room temperature and the results are presented in Fig. S3. Based on the results, in Fig. S3, it can be observed that Mo adsorption was increased with the increase of the reaction time for both adsorbents. However, the amount of molybdenum adsorption remained constant after a certain time which referred to as the equilibrium time for the reactions. Therefore, the equilibrium time for UIO-66- $\mathrm{NH}_{2}-\mathrm{SA}$ and UIO-66- $\mathrm{NH}_{2}-\mathrm{OH}$ were obtained 210 and $900 \mathrm{~min}$, respectively.

\section{The effect of pH on adsorption of molybdenum}

The solution $\mathrm{pH}$ is one of the most significant factors during the adsorption process which can affect the active site charge of the adsorbent, the ionization degree, and consequently the structure of the adsorbate molecules[20]. Thus, the solution $\mathrm{pH}$ was evaluated in the range of 3-11. The $\mathrm{pH}$ of the solution was adjusted by $0.1 \mathrm{M} \mathrm{HCl}$ or $0.1 \mathrm{M} \mathrm{NaOH}$, and the results are depicted in Fig. S4. As can be observed in Fig. S4, with the enhancement of the solution $\mathrm{pH}$ from 3-7, the amount of removed Mo increased, and then decreased upon the further increment of the solution $\mathrm{pH}$. Thus, the best results for the $\mathrm{pH}$ value for both adsorbents were 7 .

The effect of adsorbent dosage

The adsorption process was performed with various adsorbent dosages and the results are summarized in Table S1. The results indicated that Mo removal percentage was enhanced upon 
increasing of the amount of adsorbent from 10 to $100 \mathrm{mg}$. Accordingly, $100 \mathrm{mg}$ was obtained as the optimal value for both adsorbents.

\section{Effect of temperature on adsorption process}

In order to evaluate the effect of temperature, the adsorption process was studied at different temperatures in the presence of UIO-66- $\mathrm{NH}_{2}-\mathrm{SA}$ and UIO-66- $\mathrm{NH}_{2}-\mathrm{OH}$ as adsorbents (Table S2). According to the results, the amount of removed Mo reduced upon temperature increment from 298 to $318 \mathrm{~K}$. Thus, room temperature is the favorable temperature for the adsorption process. Adsorption isotherms with respect to the temperature are discussed later.

\section{The effect of Molybdenum concentration}

To elucidate the effect of pollutant, adsorption experiments were conducted with the diverse initial concentrations of Mo using UIO-66- $\mathrm{NH}_{2}-\mathrm{SA}$ and UIO-66- $\mathrm{NH}_{2}-\mathrm{OH}$ as adsorbents and the results are presented in Table S3. Based on the results, it is obvious that Mo removal decreased upon increasing Mo concentration owing to the occupation of active sites of the adsorbents.

\section{Adsorption kinetics}

The study of adsorption kinetics is one of the significant factors in the adsorption process as it provides noteworthy information about the diffusion mechanism and the reaction pathway as well as the effect of time in the removal of pollutants. For this purpose, two common adsorption kinetic models were utilized including pseudo-first-order and pseudo-second-order equations, which are illustrated completely in the supporting information.

The adsorption kinetics of UIO-66- $\mathrm{NH}_{2}-\mathrm{SA}$ and $\mathrm{UIO}-66-\mathrm{NH}_{2}-\mathrm{OH}$ were investigated through monitoring the concentration of Mo at various contact times and the results are exhibited in Figs. 
S5 and S6. Additionally, the kinetic adsorption parameters and the correlation coefficient values $\left(\mathrm{R}_{2}\right)$ calculated from the fitting line are shown in Table 3. Based on the results, the higher $\mathrm{R}_{2}$ values for the pseudo-second-order model in comparison to the pseudo-first-order model demonstrated that the results were fitted well with the pseudo-second-order kinetics model which expressed that the adsorption process proceeds via chemisorption mechanism.

Table 3 Adsorption kinetics parameters of Molybdenum using UIO-66- $\mathrm{NH}_{2}-\mathrm{SA}$ and UIO-66- $\mathrm{NH}_{2}-\mathrm{OH}$ as adsorbent.

\begin{tabular}{|c|c|c|c|c|c|c|c|}
\hline \multirow{2}{*}{ Adsorbent } & \multirow{2}{*}{$\begin{array}{c}\mathrm{C}_{0}(\mathrm{mg} . \\
\left.\mathrm{L}^{-1}\right)\end{array}$} & \multicolumn{3}{|c|}{ pseudo-first-order } & \multicolumn{3}{|c|}{ pseudo-second-order } \\
\hline & & $\mathrm{K}_{1}\left(\min ^{-1}\right)$ & $\mathrm{q}_{\mathrm{e}}\left(\mathrm{mg} \mathrm{g}^{-1}\right)$ & $\mathrm{R}_{2}$ & $\mathrm{~K}_{2}\left(\mathrm{~g} \mathrm{mg}^{-1} \mathrm{~min}^{-1}\right)$ & $\mathrm{qe}\left(\mathrm{mg} \mathrm{g}^{-1}\right)$ & $\mathrm{R}_{2}$ \\
\hline $\begin{array}{c}\text { UIO-66- } \mathrm{NH}_{2-} \\
\text { SA }\end{array}$ & 20 & $0.6 \times 10^{-3}$ & 15.49 & 0.941 & 0.021 & 31.42 & 0.995 \\
\hline $\begin{array}{c}\text { UIO-66- } \mathrm{NH}_{2}- \\
\mathrm{OH}\end{array}$ & 20 & $0.6 \times 10^{-3}$ & 13.46 & 0.770 & 0.002 & 19.27 & 0.997 \\
\hline
\end{tabular}

\section{Adsorption isotherms}

Adsorption isotherms specify the interaction between adsorbate molecules and the active site on the adsorbent surface. Among several presented isotherm models, two Langmuir and Freundlich's models have been frequently used for investigation of the experimental data of adsorption isotherms which are explained in the supporting information.

Figs. S7 and S8 demonstrate the results of Langmuir and Freundlich's models of Mo adsorption over UIO-66- $\mathrm{NH}_{2}-\mathrm{SA}$ and UIO-66- $\mathrm{NH}_{2}-\mathrm{OH}$ as adsorbents at $298 \mathrm{~K}$ in the initial concentration range of Mo from 20 to $200 \mathrm{mg} \mathrm{L}^{-1}$. Moreover, the calculated parameters for both Langmuir and Freundlich's models in the presence of adsorbents are listed in Table 4. According to the results, since the Langmuir isotherm shows a better fit with the adsorption experimental data for both adsorbent, the adsorption process occurs uniformly and in a monolayer form. 
Table 4 Isotherm parameters of molybdenum over UIO-66- $\mathrm{NH}_{2}-\mathrm{SA}$ and UIO-66-NH$-\mathrm{OH}$.

\begin{tabular}{|c|c|c|c|c|c|c|c|c|}
\hline \multirow{2}{*}{ Adsorbent } & \multirow{2}{*}{$\mathrm{T}(\mathrm{K})$} & \multicolumn{4}{|c|}{ Langmuir } & \multicolumn{3}{|c|}{ Freundlich } \\
\hline & & $\mathrm{Q}(\mathrm{mg} / \mathrm{g})$ & $\mathrm{K}_{\mathrm{L}}\left(\mathrm{L} \mathrm{mg}^{-1}\right)$ & $\mathrm{R}_{\mathrm{L}}$ & $\mathrm{R}_{2}$ & $\mathrm{n}_{\mathrm{F}}$ & $\mathrm{K}_{\mathrm{F}}$ & $\mathrm{R}_{2}$ \\
\hline UIO-66- $\mathrm{NH}_{2}$-SA & 298 & 667 & $0.6 \times 10^{-2}$ & 0.668 & 0.990 & 1.112 & 6.95 & 0.975 \\
\hline UIO-66- $\mathrm{NH}_{2}-\mathrm{OH}$ & 298 & 500 & $0.5 \times 10^{-2}$ & 0.717 & 0.995 & 1.103 & 5.25 & 0.970 \\
\hline
\end{tabular}

\section{Adsorption thermodynamics}

To investigate the desirability of the adsorption process, adsorption thermodynamics was studied. The calculation method for thermodynamic parameters has been explained in supporting information.

To evaluate adsorption thermodynamic parameters, adsorption experiments were carried out over UIO-66- $\mathrm{NH}_{2}-\mathrm{SA}$ and UIO-66- $\mathrm{NH}_{2}-\mathrm{OH}$ as adsorbents at $298 \mathrm{~K}$ and the results are depicted in Table S4. Negative values were obtained for $\Delta \mathrm{G}$ which revealed that the adsorption process occurred spontaneously.

\section{The plausible mechanism of the adsorption process}

As mentioned above, aldehyde functional groups incorporated into amine groups using imine condensation to form salicylaldehyde imine and hydroxynaphthaldehyde imine (Scheme 2, pathway I). Since molybdenum metal has the ability to combinate with suitable ligands to increase its coordination number and form octahedral geometry, in the next step after the addition of molybdate anion, molybdenum forms a Schiff base complex with the oxygen atoms of the hydroxyl groups and the nitrogen atom $\mathrm{C}=\mathrm{N}$ bonds (Scheme 2, pathway II). 


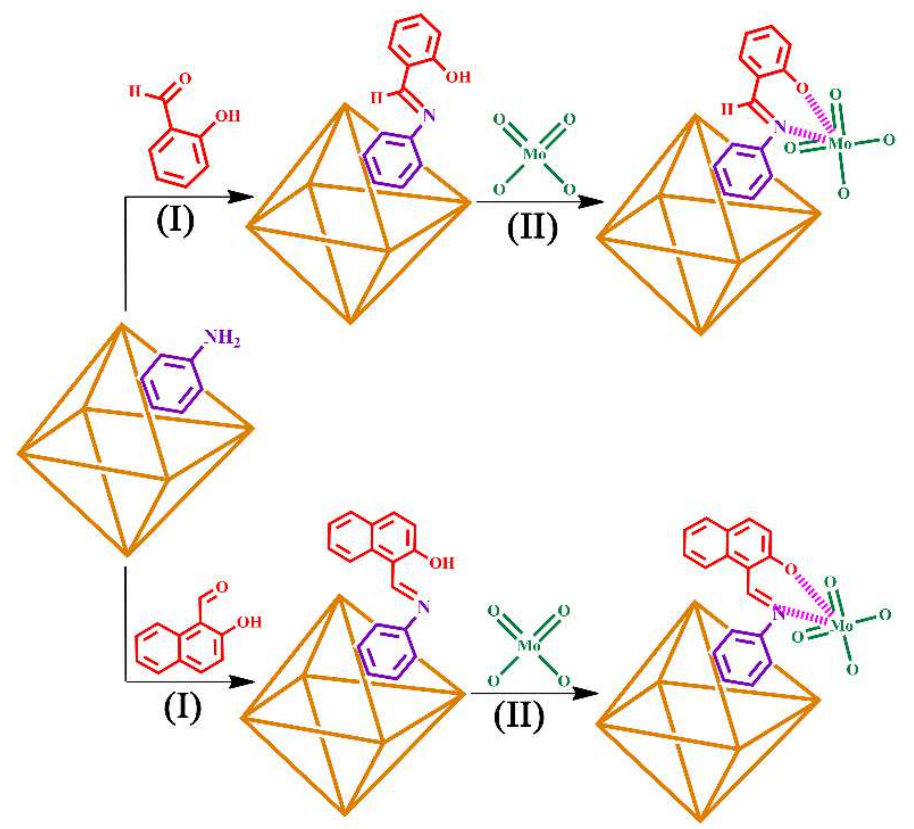

Scheme 2 The plausible mechanism for molybdenum adsorption.

\section{Comparison adsorption efficiency of the synthesized compounds}

According to the results of Table 2, Mo adsorption capacity for UIO-66- $\mathrm{NH}_{2}-\mathrm{SA}$ and UIO-66$\mathrm{NH}_{2}-\mathrm{OH}$ was obtained 666 and $500 \mathrm{mg} \cdot \mathrm{g}^{-1}$, respectively. The high adsorption capacity is mainly owing to the accessibility of the oxygen and nitrogen atoms on the formed imines for coordination with molybdate anions. The higher amount of adsorption capacity for UIO-66- $\mathrm{NH}_{2}$-SA than UIO$66-\mathrm{NH}_{2}-\mathrm{OH}$ is related to the less steric hindrance of salicylaldehyde compared to 2hydroxynaphthaldehyde functional groups.

Overall, we were able to achieve excellent results compared to others in very mild condition (room temperature and neutral $\mathrm{pH})$.

In order to investigate the amount of molybdenum leakage absorbed from the prepared adsorbents, the leaching process was studied for adsorbed molybdenum during two months. According to the 
results, the leaching amount of adsorbed molybdenum from adsorbents after a period of two months was very low and was reported to be equal to 0.7 and $1.1 \%$ for UIO-66-NH2-SA and UIO$66-\mathrm{NH}_{2}-\mathrm{OH}$, respectively.

To assess the proficiency of the prepared adsorbents in view of the recent progress, a comparison was made between our prepared adsorbents and other adsorbents in which diverse compounds were applied to adsorb molybdate anions and the results are summarized in Table 5. In our work, it can be observed that very high adsorption capacity was obtained compared to other reported literature, which is representative of the high activity and efficiency of the prepared adsorbents. The use of very mild conditions (room temperature and neutral $\mathrm{pH}$ ) to achieve the best results, is another advantage of our work compared to others.

Table 5 The comparison of adsorptive activities with some previously reported adsorbent.

\begin{tabular}{|c|c|c|c|c|}
\hline Entry & Adsorbent & Adsorbate & $\begin{array}{l}\text { Adsorption capacity } \\
(\mathrm{mg} / \mathrm{g})\end{array}$ & Ref \\
\hline 1 & Chitosan gel bead & $\mathrm{MO}(\mathrm{VI})$ & 265 & [21] \\
\hline 2 & HFO-PsAX & $\mathrm{MO}(\mathrm{VI})$ & 212 & [22] \\
\hline 3 & ZHD50 & $\mathrm{MO}(\mathrm{VI})$ & 18 & [23] \\
\hline 4 & DWTRs & $\mathrm{MO}(\mathrm{VI})$ & 44 & [1] \\
\hline 5 & Goethite & $\mathrm{MO}(\mathrm{VI})$ & 26 & [24] \\
\hline 6 & $\mathrm{ZnFe}_{2} \mathrm{O}_{4}$ nanoparticles & $\mathrm{MO}(\mathrm{VI})$ & 31 & [25] \\
\hline 7 & Mesoporous $\gamma-\mathrm{Al}_{2} \mathrm{O}_{3}$ nanospheres & $\mathrm{MO}(\mathrm{VI})$ & 56 & [26] \\
\hline 8 & MWCNT(NaOCl) & $\mathrm{MO}(\mathrm{VI})$ & 23 & [27] \\
\hline 9 & Zeolite-supported magnetite & $\mathrm{MO}(\mathrm{VI})$ & 19 & [28] \\
\hline 10 & UIO-66-NH ${ }_{2}$-SA & $\mathrm{MO}(\mathrm{VI})$ & 667 & Present work \\
\hline
\end{tabular}

Given that the present molybdenum in industrial effluents $\left({ }^{99} \mathrm{Mo}\right)$ has the same structure with the molybdenum used in this work, the prepared adsorbents can be used to adsorb radioactive molybdenum from industrial wastewater. 


\section{Conclusion}

In summary, a metal-organic framework with amine functional groups was synthesized and successfully modified with aldehyde functional groups using imine condensation. The prepared materials were utilized as an efficacious adsorbent to remove molybdenum from wastewater. This is the first report in which MOFs have been applied as adsorbents in molybdenum adsorption. High adsorption capacity was observed for both adsorbents compared with other previously reported materials. The experimental adsorption data could be well interpreted with the pseudo-secondorder kinetics and the Langmuir isotherm model. Thermodynamic parameters indicated an exothermic spontaneous mechanism for the molybdenum adsorption process. Since the present molybdenum in industrial effluents $\left({ }^{99} \mathrm{Mo}\right)$ has the same structure with the molybdenum used in this work, the prepared adsorbents can be used to adsorb radioactive molybdenum from industrial wastewater.

\section{Conflict of Interest}

The authors declare that they have no conflict of interest.

\section{References}

[1] J Lian, F Zhou, B Chen, et al. (2020) Enhanced adsorption of molybdenum(VI) onto drinking water treatment residues modified by thermal treatment and acid activation. J Clean Prod 244: 118719. Doi:https://doi.org/10.1016/j.jclepro.2019.118719

[2] DP Benu, J Earnshaw, A Ashok, et al. (2021) Mesoporous Alumina-Titania Composites with Enhanced Molybdenum Adsorption towards Medical Radioisotope Production. Bull Chem Soc Jpn Doi:10.1246/bcsj.20200282 
[3] W Chen, K Hashimoto, Y Omata, et al. (2019) Adsorption of molybdenum by melanin. Health Prev Med 24: 36. Doi:10.1186/s12199-019-0791-y

[4] N Xu, W Braida, C Christodoulatos, J Chen (2013) A Review of Molybdenum Adsorption in Soils/Bed Sediments: Speciation, Mechanism, and Model Applications. Soil Sediment Contam Int J 22: 912. Doi:10.1080/15320383.2013.770438

[5] H El-Said, H Ramadan, M Abbas, M El-Hashash (2018) 99Mo/99mTc radioisotope generator based on adsorption of 99Mo (VI) on cerium (IV) molybdate column matrix. Radiochi Acta 106: 991. Doi:https://doi.org/10.1515/ract-2018-0002

[6] T Monir, A Shahr El-Din, Y El-Nadi, A Ali (2020) A novel ionic liquid-impregnated chitosan application for separation and purification of fission 99Mo from alkaline solution. Radiochi Acta 108: 649. Doi:https://doi.org/10.1515/ract-2019-3202

[7] M Rezaee, M Mozaffari, H Haddadi, MR Pourjavid, A Semnani (2015) Extraction and Separation of Molybdenum by Using Homogeneous Liquid-Liquid Microextraction via Flotation Assistance. J Braz Chem Soc 26: 880.

[8] V Migeon, B Bourdon, E Pili, C Fitoussi (2015) An enhanced method for molybdenum separation and isotopic determination in uranium-rich materials and geological samples. J Anal At Spectrom 30: 1988. Doi:10.1039/C5JA00106D

[9] A Shimada, M Ozawa, K Yabuki, K Kimiyama, K Sato, Y Kameo (2014) J Development of a separation method for molybdenum from zirconium, niobium, and major elements of rubble samples. J Chromatogr A 1371: 163. Doi:https://doi.org/10.1016/j.chroma.2014.10.053

[10] R Brion-Roby, J Gagnon, S Nosrati, J-S Deschênes, B Chabot (2018) Adsorption and desorption of molybdenum(VI) in contaminated water using a chitosan sorbent. J Water Process Eng 23: 13. Doi:https://doi.org/10.1016/j.jwpe.2018.02.016 
[11] HE Rizk, IM Ahmed, SS Metwally (2018) Selective sorption and separation of molybdenum ion from some fission products by impregnated perlite. Chem Eng Processing Process Intensification 124: 131. Doi:https://doi.org/10.1016/j.cep.2017.12.014

[12] MM Hamed, HE Rizk, IM Ahmed (2018) Adsorption behavior of zirconium and molybdenum from nitric acid medium using low-cost adsorbent. J Mol Liq 249: 361. Doi:https://doi.org/10.1016/j.molliq.2017.11.049

[13] M Saghian, S Dehghanpour, M Sharbatdaran (2021) Cyano-bifunctional MOFs as superior catalysts for carbon dioxide fixation under co-catalyst and solvent free conditions. Appl Catal AGen 612: 117982. Doi:https://doi.org/10.1016/j.apcata.2020.117982

[14] M Saghian, S Dehghanpour, M Sharbatdaran (2020) Amine-functionalized frameworks as highly actives catalysts for chemical fixation of $\mathrm{CO} 2$ under solvent and co-catalyst free conditions. J CO 2 Util 41: 101253. Doi:https://doi.org/10.1016/j.jcou.2020.101253

[15] Y Wang, W Lin, S Yu, et al. (2021) A biocompatible Zr-based metal-organic framework UiO-66-PDC as an oral drug carrier for pH-response release. J Solid State Chem 293: 121805. Doi:https://doi.org/10.1016/j.jssc.2020.121805

[16] M Saghian, S Dehghanpour, M Sharbatdaran (2018) “Ship in a bottle” Porph@MOMs as highly efficient catalysts for selective controllable oxidation and insights into different mechanisms in heterogeneous and homogeneous environments. New J Chem 42: 12872. Doi:10.1039/C8NJ00315G

[17] M Saghian, S Dehghanpour, M Sharbatdaran (2020) Unique and efficient adsorbents for highly selective and reverse adsorption and separation of dyes via the introduction of $\mathrm{SO} 3 \mathrm{H}$ functional groups into a metal-organic framework. RSC Adv 10: 9369. Doi:10.1039/C9RA10840H 
[18] E Žunkovič, M Mazaj, G Mali, et al. (2015) Structural study of Ni- or Mg-based complexes incorporated within UiO-66-NH2 framework and their impact on hydrogen sorption properties. J Solid State Chem 225: 209. Doi:https://doi.org/10.1016/j.jssc.2014.12.033

[19] Y Wu, Y Xiao, H Yuan, et al. (2021) Imidazolium ionic liquid functionalized UiO-66-NH2 as highly efficient catalysts for chemical fixation of $\mathrm{CO} 2$ into cyclic carbonates. Micropor Mesopor Mat 310: 110578. Doi:https://doi.org/10.1016/j.micromeso.2020.110578

[20] F Doulati Ardejani, K Badii, NY Limaee, SZ Shafaei, AR Mirhabibi (2008) Adsorption of Direct Red 80 dye from aqueous solution onto almond shells: Effect of $\mathrm{pH}$, initial concentration and shell type. J Hazard Mater 151: 730. Doi:https://doi.org/10.1016/j.jhazmat.2007.06.048

[21] FA Bertoni, JC González, SI García, LF Sala, SE Bellú (2018) Application of chitosan in removal of molybdate ions from contaminated water and groundwater. Carbohydr Polym 180: 55. Doi:https://doi.org/10.1016/j.carbpol.2017.10.027

[22] J Li, D Chen, X Liao, B Pan (2019) elective adsorption of molybdate from water by polystyrene anion exchanger-supporting nanocomposite of hydrous ferric oxides. Science Total Environ 691: 64. Doi:https://doi.org/10.1016/j.scitotenv.2019.07.109

[23] H Faghihian, A Malekpour, MG Maragheh (2003) Modification of clinoptillite by surfactants for molybdate (99MO) adsorption from aqueous solutions. J Sci I R Iran 14: 239.

[24] $\mathrm{N} \mathrm{Xu}, \mathrm{C}$ Christodoulatos, $\mathrm{W}$ Braida (2006) Adsorption of molybdate and tetrathiomolybdate onto pyrite and goethite: Effect of $\mathrm{pH}$ and competitive anions. Chemosphere 62: 1726. Doi:https://doi.org/10.1016/j.chemosphere.2005.06.025

[25] Y-J Tu, T-S Chan, H-W Tu, S-L Wang, C-F You, C-K Chang (2016) Rapid and efficient removal/recovery of molybdenum onto ZnFe2O4 nanoparticles. Chemosphere 148: 452. Doi:https://doi.org/10.1016/j.chemosphere.2016.01.054 
[26] I Saptiama, YV Kaneti, Y Suzuki, et al. (2018) Template-Free Fabrication of Mesoporous Alumina Nanospheres Using Post-Synthesis Water-Ethanol Treatment of Monodispersed Aluminium Glycerate Nanospheres for Molybdenum Adsorption. Small 14: 1800474. Doi:https://doi.org/10.1002/smll.201800474

[27] Y-C Chen, C Lu (2014) Kinetics, thermodynamics and regeneration of molybdenum adsorption in aqueous solutions with $\mathrm{NaOCl}$-oxidized multiwalled carbon nanotubes. J Ind Eng Chem 20: 2521. Doi:https://doi.org/10.1016/j.jiec.2013.10.035

[28] B Verbinnen, C Block, P Lievens, A Van Brecht, C Vandecasteele (2013) Simultaneous Removal of Molybdenum, Antimony and Selenium Oxyanions from Wastewater by Adsorption on Supported Magnetite. Waste Biomass Valoriz 4: 635. Doi:10.1007/s12649-013-9200-8 


\section{Supplementary Files}

This is a list of supplementary files associated with this preprint. Click to download.

- Supportinginformation.pdf 